\title{
Scaling Innovation Hubs: Impact on Knowledge, Innovation and Entrepreneurial Ecosystems in Tanzania
}

\author{
Kelefa Mwantimwa ${ }^{1}$, Nora Ndege ${ }^{2}$, Joanes Atela ${ }^{3}$, and Andrew Hall ${ }^{4}$ \\ ${ }^{1}$ Information Studies Unit, University of Dar es Salaam, P.O.Box 35092, Dar es Salaam, Tanzania | \\ mwantimwa@udsm.ac.tz \\ ${ }^{2}$ African Centre for Technology Studies (ACTS) | n.ndege@acts-net.org \\ ${ }^{3}$ African Centre for Technology Studies (ACTS) | j.atela@acts-net.org \\ ${ }^{4}$ Commonwealth Scientific and Industrial Research Organization (CSIRO) | andrew.hall@csiro.au
}

\begin{abstract}
This study has explored the impact of innovation hubs on knowledge, innovation and entrepreneurial ecosystems. To gain deeper insights, the study adopted an exploratory case study design along a qualitative approach to conduct an empirical investigation. The study reveals a noticeable contribution of the XInnovation Hub in empowering youths in aspects of knowledge co-creation and transfer, and promotion of diverse innovations. The findings of the study also disclose that the contribution of the innovation hub in transforming innovations into entrepreneurial opportunities is still unsatisfactory. Furthermore, the findings suggest that not all start-ups emanating from the hub are taking off. This is due to various undermining factors such as financial constraints and unfriendly legal frameworks. For X-Innovation Hub to satisfactorily and sustainably contribute to national innovation systems, deliberate efforts must be made, and strategies put in place by different stakeholders such as the government. Particularly, diversification of funding sources to minimise dependence on international development funding agencies and organisations is important.
\end{abstract}

Keywords: Knowledge, Innovation, Entrepreneurship, Innovation Hub, Innovation System, Ecosystem.

Cite paper as: Mwantimwa, K.M., Ndege, N.R., Atela, J.I., Hall, A., (2021). Scaling Innovation Hubs: Impact on Knowledge, Innovation and Entrepreneurial Ecosystems in Tanzania, Journal of Innovation Management, 9(2), 39-63.; DOI: https://doi.org/10.24840/2183-0606_009.002_0005

\section{Introduction}

For so long, universities and research and development (R\&D) organizations have been considered by governments in both North and South Global as main actors in the creation and transfer of knowledge, technology, and innovation (Zuniga, 2011). In fact, innovation centres and labs are growingly becoming prevalent and potential systems for technology and knowledge transfer, and engines of socio-economic growth and transformation (Friederici, 2016; Kelly and Firestone, 2016; Hooli et al., 2016; Mwantimwa, 2019; 2008). The centers and labs have demonstrated a great deal of potential in putting generated knowledge into use, enhancing interactive learning, networking various stakeholders, and facilitation of technology transfer (Wawa, 2018; Friederici, 2016). Actually, the systems (knowledge centers and labs) are considered as cost-effective ways for fostering competitive development through co-creation, co-production, and mutual evaluation of knowledge and related products (Lange et al., 2010). The systems help to translate existing economies into knowledge-based ones (Mian and Hulsink, 2009; Mwantimwa, 2020) by helping 
to inculcate innovation, science, technology, and management development (Hans-Dieter, 2008). Besides, innovation hubs appear to "proactively support positive change with local capacity building, employment creation and empowerment" (Hooli et al., 2016, p.67) along with eliminating the gap between innovation and market developments (Radulescu, 2019).

Ultimately, international organisations and governments in the North and South Global have placed much of their focus on adopting innovation hubs, centers, and labs (Jimenez, 2019; Jimenez and Zheng, 2018: Mian and Hulsink, 2009). Interesting enough, even traditional knowledge and innovation systems (i.e. Universities and R\&D organisations) are introducing innovation centers and hubs in their knowledge systems (Wawa, 2018). This is done with the main purpose of strengthening national innovation systems (Mtunga et al., 2018). In fact, hubs are being increasingly recommended as holistic socio-economic development engines (Jimenez and Zheng, 2018; Rowe, et al., 2019; Carrillo et al., 2014; van Winden et al., 2013; Mian and Hulsink, 2009). As a result, the world is experiencing an intense proliferation of such systems. For instance, the hubs are being embraced by governments as a stamping tool for competing in the global knowledge economy (Pancholi et al., 2014), such that in 2015, the World Bank documented 117 technology hubs in Africa. One year later, the GSMA Ecosystem Accelerator recorded 314 active technology hubs in the same continent, and 287 in South and Southeast Asia excluding India (DuBoucher, 2016; Sambuli and Whitt, 2017). This is clear evidence of a surge in the number of innovation hubs in Africa. According to Jimenez and Zheng (2018, p. 95), "the discourse around innovation hubs in Africa has been characterised by an optimistic and promising view." However, the question that needs asking is: in which contexts are the hubs having substantial impact or promising?

Over the past few years, sub-Saharan Africa has witnessed a proliferation of tech hubs (Atiase et al., 2020; Kelly et al., 2016). However, while the hubs are becoming more popular because of their potential to foster socio-economic development, very few technology start-ups originating from them have had the capacity to scale up into competitive enterprises. Partly because of that, cries of unemployment continue to deepen among majority of youths in Tanzania (Mwantimwa, 2019). In fact, the contribution of innovation hubs to knowledge creation, innovation, and entrepreneurship promotion is unclear. This, however, is contributed to by the presence of an insignificant amount of literature (e.g. Wawa, 2018; Sambuli and Whitt, 2017) documenting the impact of innovation hubs in the country. This shows that research on the impact of innovation hubs is limited. While it appears to be widely believed that these hubs generate scientific knowledge and have socio-economic impacts, there are limited scientific facts to validate the belief (Atiase et al., 2020). In support, Sambuli and Whitt (2017) found that the potential technology innovation hubs have in transforming Tanzania socio-economically is an area that has not been sufficiently explored. As such, little remains known on the role the hubs have on the socio-economic growth of the country. Therefore, as part of efforts to enhance the presence of knowledge on this area, the present study explored the impact of technology innovation hubs on knowledge creation, innovation, and entrepreneurship promotion. In specific, the study explored the contribution of innovation hubs to knowledge, innovation, and entrepreneurial ecosystems and factors undermining the operation of X-Innovation Hub. The study is therefore structured along the following research questions:

1. How is the hub contributing to knowledge co-creation and transfer?

2. What is the role of the hub in innovation diffusion?

3. How is the hub contributing to entrepreneurship promotion?

4. What factors undermine the operation of the innovation hub? 


\section{Literature review}

\subsection{Concept of innovation hub}

The concept of innovation hub appears to be looked at differently by scholars from different disciplines. Hans-Dieter (2008) understands an innovation hub as an innovation ecosystem in networks of knowledge production and transfer. This is closely related to the definition provided by Mian and Hulsink (2009), stating that such a hub is a networked platform and hallmark of innovation ecosystem. The hubs are also defined as spaces for various stakeholders to co-create innovative solutions through their networks to meet social challenges (Nicolopoulou, Karatas-Ozkan, Vas and Nouman, 2015). According to Hans-Dieter (2008), these hubs are localities with knowledge architecture of high internal and external networking and knowledge sharing capabilities. Similarly, Bachmann (2014, p.23) summarises that "the innovation hub constitutes a space for people to connect, collaborate, and be inspired in a conducive environment where unlikely allies would meet by serendipity." The hubs provide space for diverse people with heterogeneous knowledge (Jimenez, 2019; Toivonen and Friederici, 2015) and are characterized by high connectedness of people with different backgrounds (Hans-Dieter, 2008). Scholars (e.g. Sambuli and Whitt, 2017; Chan et al., 2010; Chan and Lau, 2005) associate innovation hubs with labs and science parks. Sambuli and Whitt (2017) go further to relate innovation hubs with innovation incubators, accelerators, and labs. According to them, innovation hubs "are one embodiment of a larger lab conceptual space which encompasses everything from incubators and accelerators through action labs and living labs to co-working spaces."(p.5).

Collaboration, networks, co-creation of knowledge, and innovation are important elements of innovation hubs. Mian and Hulsink (2009) associate science parks and incubators with intermediating institutions that provide avenue for aligning interests of multiple stakeholders within a complex innovation ecosystem with designed regional or national objectives. In fact, innovation and knowledge hubs are always nodes in networks of knowledge dissemination and knowledge sharing within and beyond clusters likely to exchange innovation-related knowledge. The resilience and strength of these hubs seem to rest on connectivity based on strong internal and external ties (Hans-Dieter, 2008). Extant literature reveals various approaches innovation hubs employ to transfer knowledge and innovation. For example, Cooke and De Laurentis (2010) observed a number of training and support services offered cross typical sectoral and cluster boundaries. Besides, innovation hubs provide members with space for networking and sharing programs and facilities to bring their ideas to fruition (Jimenez and Zheng, 2018). In addition to being innovative spaces and tools for facilitating collaboration and knowledge transfer in eco-innovation, innovation hubs create diverse multidisciplinary networks and sustainable partnerships. Apart from that, the hubs organize various trainings to improve human resource capacity (Radulescu, 2019).

\subsection{Impact of innovation hubs}

\section{Impact on knowledge production and transfer}

Contributions innovation hubs have on knowledge co-creation, transferring, sharing and use have been documented in various prior studies (e.g. Jiménez, 2019; Jiménez and Zheng, 2019; 2018; Giudici et al., 2018; Friederici, 2016; DITOs Consortium, 2016; Hans-Dieter, 2008). Some of these have considered innovation hubs as incubators of future economic development because they help to inculcate innovation knowledge in science, technology, and management hence contributing to economic development (Hans-Dieter, 2008). For example, it has been observed that innovation hubs foster knowledge co-creation and drive interactive learning and knowledge transfer through collaborative networks (Friederici, 2016; Pancholi et al., 2014; Szogs and Mwantimwa, 2010; 
Hans-Dieter, 2008). DePropris and Hamdouch (2013) found that the hubs enhance the presence of knowledge for responding to societal needs and wants. In support, Bailey et al. (2010) informed that the hubs increase the dynamics of learning and creativity through dialectic relations. The authors further disclosed that these hubs help to create relations between local contextual and tacit knowledge, and local and trans-local codified knowledge. Using one technology and innovation hub in Zambia as their case study, Jimenez and Zheng (2018) report that innovation hubs contribute to human centered knowledge development process through collaborative learning and mentoring. On the same note, Human Science Research Council (HSRC, 2020) found that township innovation hubs in Cape Town-Philippi East of South Africa enhance bottom-up approach to knowledge creation. The hubs support participatory tacit knowledge generation, transformation, and circulation through interactive learning among a range of actors from information, formal businesses, and support organisations.

In an assessment of urban knowledge and innovation spaces, Pancholi et al. (2014) observed that hubs help to generate and disseminate knowledge in form of new ideas that contribute to the growth and nurturing of intensive knowledge activities in the global economy. Intensive knowledge activities such like business management, product designs and testing, consulting, business analysis services, promotion of products, market research, and accounting services appear to boost co-creation and transfer of knowledge and innovation (Pancholi et al. 2015, 2014; TaiShan, Chien-Yuan and Su-Li, 2013). Accordingly, these services enhance hub members' capacity for specialization; subsequently improving their evolutionary capabilities and capacity to produce tangible innovative products (Tai-Shan et al., 2013. Hans-Dieter (2008) linked knowledge hubs with knowledge clusters and found that the hubs foster proximity and face-to-face interactions that facilitate the transfer of tacit knowledge. This clearly echoes Knorr-Cetina's (1981) assertion that face-to-face interactions between experts inside and outside hubs play a decisive role in the manufacture of knowledge. Hans-Dieter (2008) insists that as meeting points for communities, knowledge hubs serve three major purposes: generating knowledge, transferring it to where it gets applied; and transmitting knowledge to other people through education and training. According to extant studies (e.g. Evgeniev and Purcell, 2020; Radulescu, 2019; Mian and Hulsink, 2009) the hubs enhance the development of viable knowledge ecosystems through creation, transfer, use, and growth.

Dwelling on five case studies of tech hubs in Africa (specifically in Nigeria, South Africa, Kenya, and Uganda) Atiase et al. (2020) report that hubs lead the way in generating new knowledge. In fact, unlike in universities, where large proportions of the big volumes of knowledge produced do not get transferred to local communities for use, the hubs appear to ensure usage of the knowledge created. This difference is associated with the fact that innovation hubs mainly contribute to generating new knowledge and innovative solutions particularly for those at the bottom of the pyramid through providing alternative channels of local knowledge production and transfer. Cherunya and Ahlborg (2020) specify channels such like business ideation, incubation technical, training, and mentoring as the ones mainly used in the production, exchange, and transfer of knowledge. According to these authors, the hubs provide new platforms that facilitate the development of knowledge economies. It is also important to note that innovation hubs such like Kelvin Grove Urban Village of Brisbane provide members with opportunities to share ideas and activities across local contexts (Loorbach et al., 2020). It appears that access to and exchange of knowledge and information among various actors boost the market uptake process and capacity building (Ridler et al., 2020; Mulas et al., 2017). In all, innovation hubs are changing the landscape of knowledge production by providing opportunities for non-university actors to create new spaces for knowledge co-creation and transfer (Atiase et al., 2020). 


\section{Impact on innovation systems}

The contribution of innovation hubs on innovation ecosystem is clearly shown in prior studies (e.g. Atiase et al., 2020; Friederici, 2016; Hooli et al., 2016). The studies show that innovation hubs play a key role of facilitating different types of innovations including social ones (Friederici, 2016). Social innovation is also referred to as societal innovation created though co-creation by multiactors in a community (Hooli et al., 2016). Assessing the role of knowledge and innovation hubs, DePropris and Hamdouch (2013) noted that the hubs strengthen the generation of technological externalities that have a positive impact on the innovation capacities of diverse sectors. Adding to this, the authors inform that the hubs facilitate the development of complex innovation systems that are globally competitive. To them, competitive incremental innovation systems are sources of sustainability and resilience for local economies. In attempt to understand the best practices of innovation hubs across Europe [i.e., Cambridge Science Park (UK), 22@Barcelona (Spain), Arabianranta (Finland), Strijp-S (Netherlands), and Digital Hub (Ireland)], Pancholi et al. (2014) report that the hubs foster creativity and interactive culture of innovation and commercialization of different products.

Besides, Hooli et al. (2016) found that interactions of various actors in hubs foster open innovation process through co-creation of products and services. In other words, literature shows that innovation hubs bring local and non-local knowledge pools together in innovation processes. Nicolopoulou et al. (2015) disclose that local community engagement drives innovative thinking and creation of new forms of socio-economic impact. For instance, studied eco-innovation virtual hubs in Romania have been found to accelerate market, products, technology, and service innovations (Radulescu, 2019). Hubs also appear to influence different types of innovations such as those to do with services and products by validating and integrating new ideas through partnerships that increase chances of success (Sambuli and Whitt, 2017). Jimenez and Zheng (2018) in an exploration of the role of Zambian innovation hubs in the nation's development reveal that surveyed innovation hubs boost diffusion of diverse innovations and creative thinking. This is in line with what has been found by Loorbach et al. (2020) that innovation hubs are enabling an environment for innovation diffusion.

Along that, innovation hubs provide members with opportunities to design solutions for local businesses through community empowerment, openness, and experimentation (Atiase et al., 2020). For example, FabLabs in London enabled thousands of people to become innovators and to contribute to social and technology innovation (construction and invention of physical objects e.g. 3D printers, laser cutters, and CNC milling machines) (DITOs Consortium, 2016). In their analysis of Seattle Innovation Hub's impact on local economy, Yeung (2019) reveal insignificant contribution of hub to firm performance. In contrast, Mulas et al. (2017) document that FabLab Barcelona promotes industry innovation by providing platforms for testing new ideas and leading to innovation within long-standing economy sectors. Besides, the Fablab was found to boost grassroot innovations through mentorship, connecting innovators to funds, provision of event space, training acceleration, and provision of access to tools for testing and prototyping products. Supporting these, Riedler et al. (2020) indicate that innovation hubs enhance members' uptake and monitoring of innovations. For example, the Copernicus Knowledge and Innovation Hubs have been found to facilitate collaborative processes from invention to innovation. Particularly, the hub helps in the opening of new trajectories and strengthening local innovation processes and products through experiential learning and interaction (Petersen, 2020) and generating new innovative solutions for those at the bottom of the pyramid (Atiase et al., 2020).

Apart from that, mixed findings have been documented in some of extant literature. While some innovation hubs are directly linked to income generation, others have an indirect link. 
Comparing innovation hubs in Zambia and United Kingdom (UK), Jimenez and Zheng (2019; 2017) expose that some innovation hubs in Zambia were not directly linked to market-based products. One of the explanations is that the main focus of some of the hubs was on capacity building and training thereby indirectly linking to market-based products. In contrast, some of innovation hubs in London were found to generate revenue and introduce social enterprises. This implies that some of the hubs were directly linked to market-based products.

\section{Impact on entrepreneurship promotion}

Besides, innovation hubs have been helping to foster interactive entrepreneurship value creation (Friederici, 2016). Noting from a recent study by Jimenez and Zheng (2018), innovation hubs have been instrumental in promoting entrepreneurship activities. In particular, the hubs have been reported to encourage people to set up their own start-ups, develop them, stimulate job creation, and generate new sources of revenue (GSMA Mobile for Development, 2014). Though the contribution of hubs to development processes are indirectly linked to employment and market based products (Jimenez and Zheng, 2018). Through provision of co-creation space, hubs help to provide entrepreneurial skills and opportunities for people with informal education. Specifically, the interaction between people with formal and informal education fosters sharing of experiences and best practices. It is worth noting that innovation hubs work as social enterprises that support start-ups, incubate new businesses, and develop and market new pro-poor products and services to improve livelihoods of communities (Hooli et al., 2016). Along that, the hubs provide a new form of community engagement that allows people to learn entrepreneurship for sustainable and competitive development (Nicolopoulou et al., 2015). Innovation hubs also promote and sustain access to financial resources, encourage entrepreneurial culture, and facilitate the creation of new companies (Radulescu, 2019). It is evident that innovation hubs have registered substantial progress in employment and wealth creation, capacity building, social inclusivity, and gender mainstreaming. In all, innovation hubs are a road map for innovation that chatters a path for entrepreneurship (Sambuli and Whitt, 2017).

\subsection{Factors undermining the operation of innovation hubs}

While the pace at which innovation hubs are being introduced is impressive, more could be seen if it was not for various constraining social, political, environmental and economic factors (Pancholi et al., 2014). It appears that inadequate skills and knowledge and lack of experience among actors are some of the critical problems associated with innovation hubs' development as a number of extant studies (e.g. Jimenez and Zheng, 2018; Chirchietti, 2017; Friederici, 2016; Gathege and Moraa, 2013) have documented. For example, lack of knowledge needed to start a business or register a company was revealed among members of surveyed Zambian hubs (e.g. Jimenez and Zheng, 2018). Lack of entrepreneurship, fundraising, product marketing, and technical, and related skills was also observed by other studies (e.g. Chirchietti, 2017; De Bastlon, 2013; Gathege and Moraa, 2013). Noting from a study by Friederici (2016), scarcity of capital investment, weak infrastructures, and inadequate skilled and knowledgeable human resources constrain the operation of innovation hubs in Africa. For example, limited budgets allocated to innovation hubs undermine attempts to increase innovation. Worse still, the funding sources available to most innovation hubs are external (Hooli et al., 2016). Besides that, recruiting and retaining the right people with the right skills appear to be challenging for most innovation hubs in the North and South Global (Berger and Brem, 2016; Rowe et al., 2019; Pancholi, et al., 2014). This informs that getting innovative, creative, and open minded individuals is problematic for innovation hubs (Berger and Brem, 2016; Poguntke, 2014; Piscione, 2013). This results in lack 
of a critical mass of technological expertise hence limiting innovation hubs' competitiveness in knowledge and innovation ecosystems (Hooli et al., 2016).

The use of a top-down approach to manage innovation hubs has been found to undermine operations of these entities. This has negative implications on inclusive innovation systems (Berger and Brem, 2016). Along that, absence of information on opportunities offered by innovation hubs is another problem as observed by Radulescu (2019). Similarly, in an examination of the role of public procurement frameworks in stimulating SMEs innovativeness, Kessy and Salema (2014) documented that difficult conditions such as requirement of very high turnover, delay in payments for delivered services, and limited transparency undermine innovativeness of SMEs. Furthermore, information gaps and limited technological awareness seem to affect the innovation hubs' operations. On this, Jimenez and Zheng (2018) observed that surveyed members of hubs in Zambia lacked information on legal aspects of investment and knowledge on copyright, company registration, and so on.

Another factor that appears to undermine innovation hubs is lack of female experts to work in technology innovation hubs. On a different note, Kelly and Firestone (2016) argue that innovation hubs' failure often comes out of a disconnection between organizational goals and business structure or between its goals and the needs of its operating environment. Challenges also arise when the aims of even a carefully modeled organisation fail to fit the needs of its contextual environment. This shows that most hubs mainly focus on offering open co-working space facilities, promoting collaboration, and conducting mentorship, with limited focus on seed funding. As a result, insufficient funding is one of the factors undermining the effectiveness of innovation hubs. In most cases, hubs generally provide no financial guarantee for their mentees, which ultimately deters potential entrepreneurs from taking their ideas into markets. On their part, Jimenez and Zheng (2017: 10) found that "despite the strong institutional support in UK, there is little sense of community and collaboration and that the hub is mostly valued by the design of the space, the resources it provides and its effect in building positive relations with clients or potential clients while the innovation hub in Zambia received very little institutional support from the formal ecosystem. This hub is embedded in an unclear environment for social entrepreneurs, with little or no support for the work that they do."

\subsection{Literature gap}

Globally, there are various prior studies on innovation/tech hubs. These studies document mixed findings on the impact of innovation hubs in different aspects. Noticeable prior studies (e.g. Atiase et al., 2020; Pancholi, 2018; Friederici, 2016; DePropris and Hamdouch, 2013; Tai-Shan et al., 2013; GSMA, 2014; Hans-Dieter, 2008) suggest that innovation hubs have a substantially support new start-ups and firms formation, and serve as sources of employment and platforms for knowledge creation and transfer, and innovation diffusion. Other prior studies (e.g.Yeung, 2019; Jimenez and Zheng, 2018; Kelly and Firestone, 2016) demonstrate the failure of some innovation hubs to substantially deliver up to their promises. Along that, some studies (e.g. Miao et al., 2015) are critical about the true achievements of innovation hubs. In all, these studies bring more confusion rather than clarity regarding the impact of innovation hubs. Therefore, the present study is an attempt to add more insights to the ongoing debate on the impact of innovation hubs in three contextual issues: knowledge creation and transfer, innovation diffusion, and entrepreneurship promotion. 


\section{Methodology}

\subsection{Research design}

To explore the impact innovation hubs have on knowledge, innovation and entrepreneurial ecosystems, an exploratory case study design was employed. This design was used because it was found suitable enough to establish new and deeper empirical insights without providing a possibility for analytical generalization (Jimenez, 2019; Bendassolli, 2013; Mwantimwa, 2017; Yin, 1994). The design is appropriate for and capable of defining the topic in a broad and contemporary context by establishing the theoretical base and shedding light on various contexts and dynamics (Pancholi et al., 2014). In addition, an exploratory case study design provides researchers with comprehensive information that helps them to gain deeper insights into a problem (Mwantimwa, 2020; 2019), ensures an in-depth exploration of diverse contexts and permits descriptive work (Jimenez and Zheng, 2018; Mwantimwa, 2019, 2017; Yin, 2009). In this design, a qualitative approach was used to specifically explore the opinions, perceptions and views of different stakeholders including innovation hub managers, directors and hub members. Despite the potentials the case study design holds, Friederici (2016) opines that the design suffers from several limitations. It appears that the design limits generalizations of findings beyond the studied empirical contexts.

\subsection{Case study}

This study focused on X-Innovation Hub as its case. This single case study approach was used to ensure an in-depth exploration and analysis of the variables under study. The was set up in 2011 as part of the TanzalCT project funded through a bilateral agreement between the governments of the United Republic of Tanzania and Finland which ended in 2016. The TanzalCT project had a number of components such as ICT capacity building, review of the national ICT policy, and innovation. The hub was started as a pilot of innovation capacity building. The hub is operating under the Tanzania Commission for Science and Technology (COSTECH). The hub, as an innovation centre, aims at fostering innovation and technology entrepreneurship through capacity building, mentoring programs, and community empowerment. Table 1 provides a brief description about the varied context of the hub:

Table 1. Case study description

Domain of interest

1. Knowledge systems;

2. Innovation systems and;

3. Entrepreneurship promotions

Intervention

1. Seeking to discover and nurture innovative solutions among youths;

2. Promoting youths' entrepreneurship ventures; and

3. Linking up youths with innovative ideas and solutions

Operating model

1. Provides mentorship of start-ups and ideas, in-house freelancers and start-ups, fabrication laboratory, internships, community outreach, and practical training 
Management of hub

Key actors
1. Managed by Hub Manager, Public Relation Officer, FabLab, Community and Communication Lead, and Technical, Operational and Partnership Lead

1. Youth innovators, entrepreneurs, freelancers, researchers, international participants

2. Funding agencies, public and private sectors

Hub members (January 2015-June 2018)
1. Gender: $667(99.6 \%)$ male and $3(0.4 \%)$ female

2. Level of education: $476(71 \%)$ bachelor degree holders, 95 $(14.2 \%)$ diploma, $70(10.4 \%)$ secondary school certificate holders, $19(2.8 \%)$ master degree, $6(0.9 \%)$ certificate holders, and $4(0.6 \%)$ advanced diploma holders
Financial resources and investment
1. External project funding support by DFID through Human Development Invention Fund (HDIF), Sida, World Bank and SeedStars Switzerland

2. Government of Tanzania through COSTECH. .
Partnership and collaborations
1. Formal and informal partnerships and collaborations

Accordingly, the main focus of the hub is to discover, nurture, and mentor youths with innovative technological solutions to problems facing Tanzania. COSTECH's vision is to transform the hub into a model 'Hub of Hubs'; creating a central node that can offer support to other hubs, labs, and innovation spaces nationally. This is evident in the Hub's state with focus on stage of development, coverage, and nature of members. In fact, the hub has unique characteristics including being at a mature stage, representing a national entity, and has many heterogeneous members. Therefore, the hub presented a good setting for exploring the uniqueness of knowledge dynamics, innovation, and entrepreneurship promotion in the country; and the challenges faced.

\subsection{Study population and sample size}

A total of 27 participants, including directors, hub managers and beneficiaries, were part of this study. The hub was purposefully selected for this study by considering its potential in what it does in the country. Extant studies (e.g. Pancholi, 2018; Friederici, 2016, Mwantimwa, 2020) support that purposeful selection of a case is done in the virtue of being either unique or information-rich. It was deemed important to gain deeper understanding on the impact the hub has on knowledge, innovation, and entrepreneurial promotion in the country. Along that, purposeful selection of the study has been done by taking into consideration characteristics of their context such like scale and stage of development (Pancholi, 2018). The study also used purposive sampling to pick respondents. This type of selection is effective in identifying and selecting individuals or groups of individuals that are particularly experienced in or knowledgeable about a particular phenomenon hence capable of providing information or data-rich narratives (Hooli et al., 2016; Pancholi et al., 
2014).

\subsection{Data collection methods, instruments and protocol}

To collect data, the study employed interpretive research methods that included in-depth semistructured interviews with the Director of COSTECH, managers of the hub, and hub beneficiaries. All the interviews, including follow-up ones with hub managers took place from May through September 2019. Sessions with the Director of COSTECH and hub managers lasted 30-45 minutes while those involving hub beneficiaries lasted 20-30 minutes. Whereas interviews with the Director of COSTECH and hub managers were face-to-face, those with hub beneficiaries were conducted through mobile phone calls. In-depth semi-structured interviews were used because they are very effective in gathering in-depth information that facilitates understanding of phenomena in the form of perceptions of different stakeholders (Pancholi et al., 2014, 2018; Mwantimwa, 2020).

The interviews focused on a combination of key themes noted in the extant literature such like knowledge and innovation transfer mechanisms and impact of innovation hubs on knowledge transfer, innovation and entrepreneurship promotion. Diverse questions were asked to the stakeholders (i.e. both general and specific questions were asked). Questions on the impact of the hub on the overall socio-economic development of the country, and ones aimed at identifying the hub's areas of priority were asked. Examples of specific questions asked to the stakeholders are: how has the hub facilitated knowledge co-creation and transfer? What are the contributions of the hub towards innovation diffusion? How has the hub promoted entrepreneurship ventures? What is the diversity of knowledge and innovation sources and flows? What approaches are employed to create and transfer knowledge and innovation, and promote entrepreneurship? How has the hub influenced some of the policy issues in the country? What do you view as the chief success of different interventions made by the hub? How have you been benefited from being a member of this innovation hub? What are the main challenges the hub faces? How can the challenges be overcome? These questions were prepared as general guidance prior to the interviews.

Proceedings of all interview sessions were recorded using a video camera alongside a smart phone audio-recording app. Besides in-depth semi-structured interviews, observation method was used to validate information provided by interviewees on facilities available in the hub and interactions of hub clients. Apart from that, desk research method or review of literature on the impact of innovation hubs on three ecosystems including knowledge, innovation, and entrepreneurship was done.

\subsection{Data processing and analysis}

During data analysis, qualitative data analysis method was used. The qualitative content and thematic analysis widely used in qualitative research as a systematic coding and categorizing of data to identify patterns within data and relationship between them was used. This systematically organizes a random set of information into distinguishable patterns of themes (Mayring, 2000). To start with, transcription of all interviews recordings was done manually to increase accuracy of results. In support of this approach, Pancholi et al. (2014) opine that "transcription of interviews is done manually to ensure the best of quality and accuracy and avoid any kind of software related technical discrepancy that might have happened due to varying accents, background noise or other interfering noise." Transcripts were read several times and notes were taken on main themes including the impact of the innovation hub on knowledge, innovation, and entrepreneurial ecosystem. Thematic analysis was employed by this study because it was found suitable for drawing out of the interview data, key themes identified in the literature reviewed. The results of this analysis have been presented in narration form. 


\section{Results}

\subsection{Case study results summary}

A number of key findings emerged from the analysis of field data obtained through in-depth interviews. Table 2 provides a summary of results on knowledge and innovation co-creation and transfer, and entrepreneurship promotion indicators. Besides the table, presents lock-ins factors, and strategies for fostering knowledge and innovation systems, and entrepreneurship promotion indicators.

Table 2. Case study results summary.

\section{Knowledge and innovation co-creation and promotion}

\begin{tabular}{ll}
\hline Key knowledge and & 1) Formal-scientific knowledge and innovations generated by \\
innovation sources & universities, schools and business companies \\
$\begin{array}{l}\text { Supporting knowledge, } \\
\text { skills and services }\end{array}$ & $\begin{array}{l}\text { 2) Human resource management, business management, } \\
\text { financial management and marketing skills, business networking, } \\
\text { access to information, and advocacy for improved business } \\
\text { environment }\end{array}$
\end{tabular}

Interlinked knowledge and innovation system

1) Knowledge and innovation system initiatives such like Dar initiatives Teknohama Business Incubator (DTBi), Tanzania Digital Innovation Youth Empowerment (TADIYE) are interlinked with the hub through COSTECH governance

2) Higher learning institutions (e.g. UDSM, MUST, UDOM), hubs (e.g. KIOTA, FabLab Nairobi) and other incubators (e.g. KINU).

Nature of partnership and

3) Formal and informal partnerships and collaborations collaborations in knowledge and innovation Nature of innovation and 1) Participatory approach, knowledge flows

2) Interactive around co-creation and co-innovation, Enabling conditions

3) Co-working space

4) Fabrication laboratory

5) Free internet services

6) Alignment to national goals around promotion of knowledge and innovation

Opportunities to strengthen national innovation, 1) Participating youths are empowered to create and share formal knowledge.

entrepreneurial and 2) Provides a platform for youths to interface with other knowledge systems knowledge sources, fosters co-knowledge and innovation creation and transfer. 
3) Public and private partnership strengthens knowledge and innovation ecosystems.

4) Collaboration between international and national agencies increases start-ups funding.

5) Direct or indirect support to develop and promote new start-ups and products

6) Promoting business ideas, plans and strengthening knowledge on business discipline, marketing, and support incubation.

7) The hub is becoming a catalyst for entrepreneurship and innovative business ideas, start-ups and products.

Indicators of the

entrepreneurship and

business promotion and success between 2011

- August 2019
1) Hub has worked with more than 5000 youths of different backgrounds since 2011 .

2) Working with over fifty (50) start-up companies, freelancers and products.

3) Implemented more than thirty (30) projects that involved 675 students through internship programme.

4) Ten (10) companies graduated from incubation programmes.

5) Five (5) companies secured seed fund.

6) Fifteen (15) companies participated in mentoring programme.

7) Worked with over 1000 youths in community outreach activities.

\section{Lock-ins and contextual factors (undermining factors)}

Lock-ins

1) While knowledge and innovation co-creation and transfer outcomes are explicitly aimed for, there are inevitable losers in the innovation transition to a more product and market based supply chain.

2) Knowledge lock-ins and related innovation trajectories lock-ins arising from dependency on formal knowledge and innovation systems

3) Lack of clarity regarding how the hub can sustain itself in the absence of external project funding.

4) There are concerns that externally funded projects skew knowledge and innovation choices and development priorities and can direct capabilities away from local issues.

5) The hub is not effectively collaborating with private sector actors because of bureaucracy

6) Systematic structure of operation undermines the hub's efforts to speed up knowledge and innovation co-creation 
7) Participation of female youths is very unsatisfactory

\section{Strategies to foster knowledge and innovation systems)}

What needs more attention 1) Effective employment of PPP approach to foster national innovation system

2) Diversification of funding sources from local agencies and the government of Tanzania

3) Deploying unstructured approach to foster knowledge and innovation co-creation

Source: Fieldwork, 2019

\subsection{Key informants' narratives and interpretation}

To explore the impact of X-Innovation Hub on knowledge and innovation co-creation and transfer, and entrepreneurship promotion; key informants were asked to provide their views. A mixture of findings has been generated from interview narratives. Whereas a proportion of key informants were of the view that the hub has a significant contribution on knowledge, innovation and entrepreneurial promotion, others were of an opposing view, citing a number of flaws that undermine the hub's ability to enhance knowledge, innovation and entrepreneurial ecosystems. The first part of this section presents key informants' views on the impact of the innovation hub on knowledge, innovation and entrepreneurship ecosystems while the second one provides opinions on factors undermining the same.

\section{Impact of the hub on knowledge, innovation and entrepreneurial ecosystems}

In-depth key-informant interview results suggest that the hub has made a contribution to national knowledge, innovation and entrepreneurial ecosystems. Its contribution has been noticed in different areas such as development of various products, offering working space, national policy formulation, and network building and knowledge transfer. The results also reveal that a significant role is played by the hub in aspects such like offering mentorship, internship and outreach programmes, supporting innovation processes and management of new start-ups, promoting youths' entrepreneurship ventures, and providing access to mini fabrication laboratory. Speaking on the hub's contribution, one key informant was heard sharing the following words:

... the hub has successfully implemented different projects. Notable examples include building the first electronic waste 3D printer in East and Central Africa and successfully implementing the drone project. As a result, we became the winners of 2014-2015 best innovation hubs. We have been working with reputable organizations, hubs and institutions to launch new start-ups [Male; hub management, public; id no. 26].

In his words, another key informant narrated that:

The hub has been facilitating a number of activities related to knowledge and innovation creation and transfer. To date, the hub has directly or indirectly contributed to and played a key role in a number of start-ups, and the development and promotion of products. For instance, STICLab, SomaApp, and Bela Vendor Sanitary Pad Vending Machines are some of the products the hub has contributed to through mentorship and in-house freelancer and incubation. The vending machines have resulted in the repackaging of sanitary pads into single-pad packages which are loaded in the machines which are installed in washrooms. To get a pad when needed, women need to slot a coin which makes the machines eject one. Whereas STICLab came up with automated water vending machines, SomaApp created an 
innovative product that connects users with funding opportunities which are accessed through different gadgets such mobile phones and computers with internet [Male; hub management, public; id no. 26].

From these voices, it can be clearly observed that the hub supports diverse knowledge and innovation creation and transfer in form of product, process, and marketing innovations. The interviews also revealed that the hub has also facilitated the development of automated water vending machines in addition to the just mentioned 3D printer, app for accessing funding, and pad vending machines. The interviews have further revealed that the hub goes beyond facilitation of product-related innovations by being involved in processing and promoting of the products. Apart from that, the hub has been found to use mentorship and outreach programs to foster knowledge transfer and innovation. Generally, it has been noted that the hub has contributed to the introduction of new start-ups and products while also helping to strengthen existing ones so as to improve their quality and that of the services and process associated with them. Regarding mentorship, one of the key informants summarised that:

........business mentorship program provides young innovators with guidance on their start-ups and business ideas. The hub assists participants to identify a mentor who provides guidance to individuals and teams looking to scale-up their business ideas and early-stage start-ups for profit and non-profit making at the hub. In connection to this, the hub encourages in-house freelancers and start-ups as individuals and teams working on their early-stage businesses, offering ICT services and developing products.

Another key informant had the following to say on mentorship and capacity building programs:

The hub fosters innovation and technology entrepreneurship through capacity building, mentoring and community empowerment programs. For example, we help to discover, nurture and mentor youths with innovative technological solutions to problems facing the nation. In general, youths get opportunities to acquire business education on matters such as how to deal with clients' attitudes, negotiating skills, and planning. The hub is becoming a catalyst for entrepreneurship and innovative business ideas, start-ups, and products.

The approaches employed by the hub appear to foster knowledge transfers hence stimulating innovation and entrepreneurial ventures. Guidance from mentors coupled with the infrastructure support the hub offers help to empower youths with innovative and entrepreneurial ideas. Interview quotations disclose that mentorship, outreach, and in-house training programs provide youths with knowledge that allows them to roll out their entrepreneurial ideas through process, product, organization, and market innovations. The business education provided by the hub seems to be propelling the implementation of business ideas. Furthermore, the hub was reported to have a community outreach program used to increase awareness and enhance innovation ecosystems in Tanzania. To strengthen network building, the hub provides a space where graduates, students, and people from different settings meet. This importance of this was acknowledged by most of the participating beneficiaries. Evidently, one of the beneficiaries narrated that:

The hub offers working space to all members for free charge. This is an avenue for graduates and students with diverse backgrounds to meet and establish networks and practice teamwork. In most cases, we have the opportunity to exchange knowledge and experience. Every day, we experience new challenges in our professions. Meeting other graduates and students from different institutions helps us to find innovative solutions for the challenges and problems we encounter on daily basis. Networking is very important for sharing our challenges and experiences [Male, aged 29, beneficiary, id no. 3]. 
This was supported by another beneficiary who said that:

The hub helps a lot when it comes to network building and knowledge transfer. Interacting with other graduates and students provides us with opportunities to learn from each other. Frankly speaking, the hub mainly facilitates networking and knowledge transfer among the youths who visit it. Also, the hub provides opportunities for exposure since sometimes it receives students [Male; aged 27, private sector, id no. 21].

On the same note, another key informant narrated that:

In fact, the hub provides individuals and teams with the opportunity to use the mini fabrication laboratory to develop makertronic solutions. I have actually used this facility to develop different market software. Sometimes, the hub hosts different events to allow youths and development actors to discuss development problems and solutions. I have participated three times in such events. In all, the hub offers co-working space, trainings, and business advice; organises different events; and conducts community outreach programs.

Based on these narrations, the co-working space provided by the hub provides members with opportunities to network, exchange ideas, practice teamwork, and share and transfer knowledge. In addition to networking space and mini fabrication laboratory, it was observed that the hub provides members with access to internet services which in turn enhance access to and use of information and knowledge resources. The supporting infrastructure offered by the hub, particularly the mini fabrication laboratory and internet services seem to play a pivotal role in stimulating knowledge access, creation, use and transfer, and innovation development.

Along that, the hub management indicated to participate in national policy making process. This was clearly stated by key informants during interview sessions. In his words, one key informant narrated that:

Somehow we are part of the policy making process though not fully. For example, we have been working with the National Economic Empowerment Council (NEEC) in providing direction on what should be done in terms of policies related to national innovation systems. We are involved in different events related to policy issues [Male; hub management, public; id no. 26]

This quotation indicates that the hub is involved in policy formulation. This is evidence that the hub's contribution in the aspect of innovation ecosystems is recognised by government bodies such like NEEC. In fact, interviewees stated that the hub has provided some inputs in the revised National ICT Policy of 2016. This speaks volumes regarding the innovation hub's potential to contribute towards the development of the national innovation system.

\section{Undermining factors of innovation hub functionality}

The studied hub is not resistant to factors that undermine operations of entities of its nature. Based on narrations from interviews of the case study, the effectiveness of the hub is undermined by a number of factors. For example, shortage of human resources, lack of legal entitlement, being directly embedded in the government, inadequacy of infrastructure, and financial constraints have been found to slow down the innovation hub. One key informant from the hub testified that:

Our hub is directly embedded in the government system. This, sometimes, limits operations, collaborations, and the speed of implementing our programs and projects. For example, currently we are not effectively collaborating with private sector actors because of bureaucracy. The private sector is discouraged by the long processes they have to be involved in when 
implementing programmes and projects. The private sector wants things to move fast [gender: male; position: management of hub; sector: public; id no.26].

In support of this narration, another key informant added that:

The government mainly operates in a structured system or model. However, innovation does not always follow a structured system. In many cases, innovation operates in unstructured systems. Operating in a structured model is one of the stumbling blocks for efforts to foster innovative solutions and the development of the hub [Male, management level, public sector; id no. 1].

These narrations inform that the effectiveness and performance of the hub are undermined by the structured model under which the government system operates. This was mentioned to discourage the involvement of private sector actors whose operations usually run faster. According to interview responses, inadequacy of working infrastructure and facilities is another force working against the innovation hub. For example, facilities available in the mini-fabrication laboratory offer support for software engineering, computer engineering, telecommunication and ICT innovators only. Other graduates with different backgrounds such as mechanical engineering are lacking facilities to support their initiatives. This was magnified by one hub beneficiary who pointed out that:

For those who pursued computer engineering and IT, the hub is an important place. For people like me who graduated in mechanical engineering, it is hard to benefit enough from the hub. I cannot develop any mechanical product in the hub because the environment created does not support that. I only benefit from using the space and networking with other graduates [male, aged 29, hub member; private sector; id no. 22].

Another beneficiary added that:

The hub's programs have limited scope. You can only depend on the hub when you want to come up with IT solutions. You must proactively seek help from other graduates and students if you are to develop solutions of other nature. Otherwise, you will end-up without gaining anything from the hub. In other words, for other graduates and students, their efforts determine their success, not the hub [Male; aged 30; hub member, id no. 5].

These narrations inform the hub does not adequately cater for knowledge needs of all participants. As such, the potential of those that are not optimally served by the hub is not effectively developed to allow them to implement their start-ups. One beneficiary attested to this as follows:

At the beginning, the hub was so strong and very effective. Interactions with students and graduates from different parts of the country were very strong. In general, the hub is not offering knowledge-intensive programmes to allow someone to effectively implement an idea or start-up. This is because the hub has inadequate resources to effectively implement such programmes [gender: male; age: 32; position: hub member; sector: private; id no. 21].

In support, another key informant narrated that:

The hub mainly depends on financial support from international agencies and organisations. This, in turn, determines the types of projects and programmes to implement. Frankly, the capacity of the hub is undermined by limited funding for running diverse programmes and investing in infrastructure and facilities.

From these quotations, one can note that financial dependency constrains the implementation of various programs such as training and outreach. It was also noted from interview sessions 
that ineffective communication between hub personnel and applicants undermines the potential contribution of the hub. Also, it was stated that:

There are too many start-ups in Tanzania but their survival is questionable. Markets for start-ups are limited. Most youths have goods business ideas and are developing different software and other products which only end up facing stiff competition from imported ones. Some end-up selling their software and products at prices too low to allow them to recoup the time and money invested. The main barrier for their growth is in form of legal frameworks such as Procurement (Amendment) Regulations of 2016 which discourages innovative youths in tendering processes. For example, the regulations requires someone with large capital and experience; both which youths lack [gender; male; age: 29; position: hub member; sector: private, id no.5].

Obviously, this undermines the efforts made by X-Innovation Hub to strengthen knowledge and innovation systems. Although the hub has managed to establish a partnership with different knowledge and innovation system actors, its weak linkage with the private sector to fostering knowledge and innovation ecosystem is clearly a problem. As a result, informal networking and linkage have been found to dominate. That aside, shortage of experts, lack of legal entitlement of the hub, and lack of awareness on the hub's programmes were the other stumbling blocks. Apart from that, it has been noted that shortage of human resources to manage the hub is another challenge. As it appears, experts with experience, exposure, and competencies to operate the hub are scarce. Interviewees associated this with the novelty of innovation hub concept in the country. According to them, the concept of innovation hub is new to many professionals including experts in industry, technology, engineering, and human resource management in Tanzania.

\section{Discussion}

This study explored the impact of innovation hubs on knowledge, innovation and entrepreneurship ecosystems in Tanzania. The impact the studied innovation hub has on knowledge creation, transfer, and use; and innovation and entrepreneurship promotion is not one to underestimate. The co-working space provided by the hub is an important avenue for building networks and collaborations, which in turn are instrumental in knowledge co-creation, interactive learning, and knowledge transfer and use. Earlier studies (for example, Radulescu, 2019; Friederici, 2016; Pancholi et al., 2014; Mian and Hulsink, 2009) support that such hubs enhance the development of viable knowledge systems through co-creation, transfer, and use in collaborative networks. However, the findings of this study do not support Bailey's et al. (2010) findings that stated that innovation hubs foster the transfer of both tacit and explicit knowledge. The main explanation for the discrepancy is that the members of the studied innovation hub are from formal knowledge systems such like schools, college and university graduates. As a result, the co-created, transferred and used knowledge is mainly explicit. This suggests that the linkage between formal and informal knowledge systems is not well established by the hub.

Regarding innovation, the findings have revealed a direct and indirect impact of the innovation hub on innovation co-creation, transfer and promotion. As also found by prior studies (e.g. Nicolopoulou et al., 2015; Radulescu, 2019; Sambuli and Whitt, 2017), the hub fosters co-creation of products and services alongside commercialization. Products such like makertronic solutions, STICLab, SomaApp, and Sanitary Pad Vending Machines are evidence of product and service innovation. Collaboration and interactive learning enhanced by co-working networks alongside seed fund support are important ingredients for co-created and promoted innovations. The findings 
further suggest that the main focus of the studied hub is ICT and IT related knowledge and innovation co-creation, transfer and promotion. So, what are the explanations for this? The explanations are threefold. Firstly, the types of products, process, and services facilitated by the hub are ICT/IT oriented. Secondly, the available infrastructure and facilities such as the mini-fabrication laboratory support ICT/IT oriented innovations. Thirdly, it was noted that a large proportion of the hub's members are graduates from ICT/IT programmes. From these reasons, it is worth arguing that the hub does not foster wide multidisciplinary knowledge and innovation co-creation, transfer and promotion. Exploring an incubation perspective on social innovation, Nicolopoulou et al. (2015) revealed that local community engagement in innovation systems drive different types of innovations. However, this is not the case for the studied innovation hub. The findings further expose that engagement of the hub in the amendment of diverse policies is an indication of inclusive national innovation system.

Apart from that, the findings reveal different ways used by the hub to promote entrepreneurship culture and activities. Supporting existing and new start-ups, commercializing products and services, providing business education, hosting incubations, and offering outreach, mentorship, in-house freelancer, and internship programmes are the hub's notable ways for doing so. Extant studies (e.g. Pancholi, 2018; Jimenez and Zheng, 2018; Hooli et al., 2016) support that through co-working space, incubation and interactive learning, hubs promote entrepreneurial skills and knowledge. Besides, existing studies show that hubs provide financial management skills and promote access to financial resources (see also, Radulescu, 2019). Noticeably, interaction between people with formal and informal education systems seems to be limited at the hub. This was evident in the absence of registered hub members with informal education. This informs that graduates from formal education systems were the main innovation hub beneficiaries. As such, it is understandable to conclude that the hub is missing out on a chance to maximise its impact because as documented in a study by Hooli et al (2016), interactions between people with formal and informal education foster interactive learning, build experience, and create platforms for sharing best practices which in turn promote entrepreneurship culture. On the same, Nicolopoulou et al. (2015) reveal that innovation hubs offer a new model of local community engagement in learning entrepreneurship for sustainable and competitive development. In all, findings from the present study show that the innovation hub boosts entrepreneurship culture, creation of new start-ups, and promotion of products and services as also registered by Radulescu (2019) and Hooli et al.(2016).

Despite the substantial efforts made by the hub to promote innovation and entrepreneurship activities, the findings reveal that until the time of data collection, the hub had only helped in the successful development of an unsatisfactory number of start-ups, products, and services. This discloses that not all supported and incubated start-ups were taking off. Factors that undermine the effectiveness of the innovation hub are many. The findings reveal inadequacy of financial resources invested and dwindling budgets allocated to the hub as the main stumbling blocks for the implementation and support of innovative programmes, start-ups, ideas, products, and services (see also, Friederici, 2016; Hooli et al., 2016). In this aspect, Friederici (2016) testifies that incremental innovation is undermined by limited budget allocation. The factor contributing to the financial challenges faced by the hub is the lack of diversification of sources of money. As such, the hub has limited supporting facilities and infrastructure hence its limited capacity. In fact, the syndrome of being financially dependent on international funding agencies and organisation is clear this study's findings. Likewise, Hooli et al. (2016) report that innovation hubs in developing countries rely on external funding and support. This puts the sustainability of programmes and activities introduced by the hub into question.

Furthermore, poor linkage between formal and informal knowledge and innovation systems 
hold back efforts to bring out sustainable and competitive innovations for local and international communities. Along this, unclear public private partnership in running the hub is another one of the hurdles keeping the hub from excelling. Poor gender mainstreaming in innovation co-creation was evident in the large number of registered male hub members who participated in diverse knowledge and innovation co-creation compared to females. Apparently, poor information on opportunities offered by innovation hubs is another problem for these entities (Radulescu, 2019). However, it is unclear as to whether the gender is a result of lack of awareness about the hub's activities and programmes among females or some other factors. Either way, this leaves a dent on the hub's impact on knowledge, innovation, and entrepreneurial ecosystems in the country. In fact, this state is different from what was reported in prior studies (such as Berger and Brem, 2016, Radulescu, 2019; Piscione, 2013). As also noted by Friederici (2016), the findings suggest that shortage of experts to operate the innovation hub is another notable stumbling block. This goes along with the fact that innovation hubs are new to many people in Tanzania. Apart from that, seemingly agreeing with Kessy and Salema (2017), the study has found that public procurement frameworks undermine the hub's tendering processes, which, in turn, hold back SMEs innovativeness.

\section{Conclusion and recommendations}

Without a doubt, the potential of the innovation hub in empowering youths to co-create and transfer knowledge, and promote diverse innovations has been demonstrated in this study. However, the hub's role in entrepreneurship promotion, specifically its contribution to transforming innovations into entrepreneurial opportunities is unsatisfactory. This is evidenced by the failure of a number of start-ups to take off due to various undermining factors such as financial constraints and unfriendly legal frameworks. As a result, youth unemployment remains one of the longstanding problems in the country. However, despite the findings of this study, the question on tangible impact of the innovation hub needs further research. That is necessary because this study did not extensively explore the subject. Similarly, the question of why most of the hub's beneficiaries were males has not been answered by the present study. As such, a study on gender mainstreaming in innovation systems such like innovation hubs appears imperative.

For X-Innovation Hub to contribute to competitive and sustainable national innovation systems, deliberate efforts by different stakeholders, such as the government, should be made. In particular, diversification of funding sources should be done so as to minimise dependence on international development funding agencies and organisation. This calls the government, through COSTECH, to allocate adequate funds for the hub's infrastructure and activities. This is important for sustaining the innovation hub and its operations. Along this, there is a need to increase the number of experts to run the hub as the current number of experts does not suffice the hub's needs. To enhance an inclusive innovation system, strengthening public-private partnership, linking formal and informal innovation systems, and gender mainstreaming in innovation systems are quite important. The structured model of operation used by the government appears to hold back the efforts of the hub to effectively implement various programs and collaborate with private sector actors. As such, deploying an unstructured model to run the hub will most likely speed up the implementation of diverse programmes.

\section{Study limitations and suggestions for future study}

The study has limitations that need to be taken aboard. For example, although the study highlights the impact of innovation hubs in knowledge production and transfer, and promotion of innovation 
and entrepreneurship, the use of a case study design limits the generalizability of its findings. The adoption of a single case study and cross-sectional designs instead of using multiple cases and a longitudinal design that could more effectively identify the impact of innovation hubs limit the scope of the study findings. Besides, the study did not extensively explore the tangible impact of the innovation hub. This is a limitation for drawing a clear picture on the impact of innovation hubs in the country. Despite the limitations the study brings insights are worth considering in further explorations of innovation hubs.

In fact, there are a number of questions that the present study leaves unanswered, as well as a number of new ones it raises. Therefore, it is suggested that future studies to address some of these limitations of the present study are of worth for the purpose of advancing knowledge on knowledge, innovation and entrepreneurship ecosystems. Future studies to utilize mixed designs and approaches (i.e. qualitative and qualitative) that might rely on large quantities of data are quite important. Accordingly, conducting comparative case studies on the impact of innovation hubs is very important to gain more insights. Equally important is long-term follow-up research to assess the tangible impact of innovation hubs on knowledge, innovation and entrepreneurship.

\section{Acknowledgements}

This material has been funded by the UK Government through the East Africa Research and Innovation Hub, Foreign, Commonwealth and Development Office (FCDO). The views expressed do not necessarily reflect the UK Government's official policies. The Knowledge Systems Innovation (KSI) project is managed by the Natural Resources Institute (NRI) of the University of Greenwich in partnership with the African Centre for Technology Studies (ACTS) in Kenya, the Commonwealth Scientific and Industrial Research Organisation (CSIRO) of Australia, the Science Policy Research Unit (SPRU) of the University of Sussex and the Department of Science, Technology, Engineering and Public Policy of University College, London (UCL STEaPP).

\section{References}

Atiase, V,Y., Kolade, O., \& Liedong, T.A. (2020). The emergence and strategy of tech hubs in Africa: Implications for knowledge production and value creation. Technological Forecasting and Social Change. https: https://www.doi.org/10.1016/j.techfore.2020.120307

Bailey D., Bellandi M., Caloffi A., \& De Propris, L. (2010). Trajectories of change for mature manufacturing regions in Europe: the role of place-renewing leadership. Policy Studies, 31(4), 457-474.

Bendassolli, P.F. (2013). Theory building in qualitative research: reconsidering the problem of induction. Forum Qualitative Sozial for schung/Forum: Qualitative Social Research, 14 (1), 1-50.

Berger, A., \& Brem, A. (2016). Innovation hub how to: Lessons from Silicon Valley. Global Business and Organizational Excellence, 58-70. https://www.doi.org/10.1002/joe

Carrillo F., Yigitcanlar, T., Garcia, B., \& Lonnqvist, A. (2014). Knowledge and the city: concepts, applications and trends of knowledge based urban development. New York: Routledge.

Chan, K., \& Lau, T. (2005). Assessing technology incubator programs in the science park: the good, the bad and the ugly. Technovation, 25(10), 1215-1228

Chan, K., Oerlemans, L., \& Pretorius, M. (2010). Knowledge exchange behaviours of science park frms: the innovation hub case. Technology Analysis \& Strategic Management. 22(2), 207-228. 
Cherunya, P.C., Ahlborg, H., \& Truffer, B. (2020). Anchoring innovations in oscillating domestic spaces: Why sanitation service offerings fail in informal settlements. Research Policy, 49 (1):1-16.

Chirchietti, N. (2017). The role of innovation hubs taking start-up from ideas to business: The case of Nairobi, Kenya. IZNE Working Paper Series, Nr.17/7. Bonn-Rhein Sieg University of Applied Sciences

Cooke, P., \& de Laurentis, C. (2010). Trends and drivers of the knowledge economy. In Cooke, P. et al (eds.) Platforms of innovation: Dynamics of new industrial knowledge flows, pp.1-26

De Bastion, G. (2013): Technology Hubs. Creating space for change: Africa's technology innovation hubs. Edited by Deutsche Gesellschaft für Internationale Zusammenarbeit (GIZ) GmbH. Bonn. Available online at https://10innovations.alumniportal.com/fileadmin/10innovations/dokumente/GIZ 10innovations-01_Technology-Hubs-Brochure.pdf, checked on 3/15/2016.

DePropris, L., \& Hamdouch, A. (2013). Regions as knowledge and innovative hubs. Regional Studies, 47 (7), 997-1000

DITOs Consortium (2016). Doing it together science: D3.2 innovation hubs. University College London: London.

Du Boucher, V. (2016). A few things we learned about tech hubs in Africa and Asia', GSMA. http://bit.ly/2aXmn6Q.

Friederici, N. (2016). Innovation hubs in Africa: assemblers of technology entrepreneurs. DPhil Thesis, University of Oxford

Gathege, D. \& Moraa, H. (2013). Draft Report On Comparative Study on Innovation Hubs Across Africa. Edited by iHub Research. Accessed on 1/18/2016 http://research.ihub.co.ke/uploads/ 2013/may/1367840837_923.pdf

Giudici, A., Combs, J. G., Cannatelli, B. \& Smith, B. R. (2018). Successful scaling in social franchising: The case of Impact Hub. Entrepreneurship Theory and Practice. https://www. openaccess.city.ac.uk/20267/

GSMA (2014). Digital entrepreneurship in Kenya. Accessed 10th July 2020 http://www. gsmaentrepreneurshipkenya.com/

GSMA Mobile for Development. (2014). Digital entrepreneurship in Kenya. Accessed 18th January 2021. https://www.gsma.com/mobilefordevelopment/wpcontent/uploads/2014/02/ Digital-Entrepreneurship-in-Kenya-2014

Hans-Dieter, E. (2008). Knowledge hubs and knowledge clusters: designing a knowledge architecture for development. ZEF Working Paper Series, No. 27, University of Bonn, Center for Development Research (ZEF), Bonn. Accessed from: http://nbn-resolving.de/urn:nbn:de: 0202-20080911278

Hautama, A., \& Oksanen, K. (2015). Sustainable innovation: Competitive advantage for knowledge hubs. In P. Lappalainen, M. Markkula, \& H. Kune (Eds.), Orchestrating regional innovation. Helsinki: Aalto University. pp. 87-103.

Hooli, L., Jauhiainen, J.S., \& Lähde, K. (2016). Living labs and knowledge creation in developing countries: Living labs as tool for socio-economic resilience in Tanzania. African Journal of Science, Technology, Innovation and Development, 3 (1), 61-70.

Jiménez, A. (2019). Inclusive innovation from the lenses of situated agency: insights from 
innovation hubs in the UK and Zambia. Innovation and Development, 9 (1), 41-64.

Jiménez, A., \& Zheng, Y . (2017). A Spatial Perspective of Innovation and Development: Innovation Hubs in Zambia and the UK. 14th International Conference on Social Implications of Computers in Developing Countries (ICT4D), May 2017, Yogyakarta, Indonesia. pp.171-181, ff10.1007/978-3-319-59111-7_15ff. ffhal-01650083f

Jiménez, A., \& Zheng, Y. (2018). Tech hubs, innovation and development. Information Technology for Development, 24 (1), 95-118.

Kelly, T., \& Firestone, R. (2016). How tech hubs are helping to drive economic growth in Africa (Background Paper for the World Development Report 2016: Digital Dividends). Accessed from: https://openknowledge.worldbank.org/bitstream/handle/10986/23645/WDR16-BPHow-Tech-Hubs-are-helpin pdf

Kessy, S., \& Salema, G. (2014). The role of public procurement framework in stimulating SMEs innovativeness in Tanzania. Operations Research Society of Eastern Africa (ORSEA) Journal, 4 (1), 1-39.

Knorr-Cetina, K. (1981). The manufacture of knowledge: An essay on the constructivist and contextual nature of science. Oxford: Pergamon Press.

Lange, A., Handler, D., \& Vila, J. (2010). Next generation clusters: creating innovation hubs to boost economic growth. White Paper, Cisco Internet Business Solutions Group (IBSG).

Loorbach, D., Wittmayer, J., Avelino, F., von Wirth, T., Frantzeskaki, N. (2020). Transformative innovation and translocal diffusion. Environmental Innovation and Societal Transitions, 35, 251-260.

Mian, S., \& Hlsink, W. (2009). Building knowledge ecosystems through science and technology parks. IASP World Conference on Science and Technology Parks. June 1-4, 2009, The Research Network Triangle, New York, USA.

Mtunga, P.M., Were, S., \& Ogada, K. (2018). Challenges affecting innovation in the technology incubation hubs in Kenya. European Journal of Business and Strategic Management, 3 (4), 15-23.

Mulas, V., Nedayvoda, A., \& Zaatari, G. (2017). Creative community spaces : Spaces that are transforming cities into innovation hubs. World Bank, Washington, DC. (C) World Bank. https://openknowledge.worldbank.org/handle/10986/28329 License: CC BY 3.0 IGO."

Mwantimwa, K. (2019). Higher institution education and entrepreneurial knowledge acquisition of graduates in Tanzania. Current Politics and Economics of Africa, 12(2/3), 209-229.

Mwantimwa, K. (2019). ICT usage to enhance firms' business processes in Tanzania. Journal of Global Entrepreneurship Research, 9(46), 1-23. https://doi.org/10.1186/s40497-019-0170-6.

Mwantimwa, K. (2020). Livelihood information and knowledge needs, access, and exchange in rural communities in the Bunda District, Tanzania. Rural Society, 29 (1), 30-43. https: //doi.org/10.1080/10371656.2020.1744271

Mwantimwa, K. (2008). The relationship of indigenous knowledge and technological innovation to poverty alleviation in Tanzania. Paper presented for the VI Globelics Conference, September 22-24 2008, Mexico City. https://smartech.gatech.edu/handle/1853/36892

Mwantimwa, K. (2017). Auditing information and knowledge accessed and utilised from community resource centres in Bunda District, Tanzania. University of Dar es Salaam Library Journal, 12 (1), 
28-47.

Nicolopoulou, K., Karatas,-Özkan, M., Vas, K., and Nouman, M. (2015). An incubation perspective on social innovation: the London Hub-a social incubator. Research and Development Management, 47 (3), 368-384.

Pancholi, S. (2018). A conceptual approach for place making in knowledge and innovation spaces: Case investigations from Brisbane, Melbourne and Sydney: PhD Thesis: Queensland University of Technology.

Pancholi, S., Yigitcanlar, T., \& Guaralda, M. (2015). Place making facilitators of knowledge and innovation spaces: insights from European best practices. International Journal of KnowledgeBased Development, 6(3), 215- 240.

Pancholi, S., Yigitcanlar, T., \& Guaralda, M. (2014). Urban knowledge and innovation spaces: concepts, conditions and contexts. Asia Pacific Journal of Innovation and Entrepreneurship, 8 (1), 15-18.

Petersen, I. (2020). Opening up new trajectories in the informal sector: Can township innovation hubs make the difference? Poilcy Brief. Accessed 15th October 2020: http://www.hsrc.ac.za

Piscione, D. P. (2013). Secrets of Silicon Valley: What Everyone Else Can Learn from the Innovation Capital of the World. New York: Palgrave Macmillan.

Poguntke, S. (2014). Corporate Think Tanks: Zukunftsgerichtete Denkfabriken, Innovation Labs, Kreativforen \& Co. Wiesbaden, Germany: Springer.

Radulescu, I. (2019). Research concerning the achievement of eco-innovation virtual hub tools to increase Romanian economic environment competitiveness. IOP Conference Series: Materials Science and Engineering, 514: 012038. doi:10.1088/1757-899X/514/1/012038.

Riedler, B., Lang, S., Zeil, P., Miguel-Lago, M., Schroder, C., Politi-Stergiou, N., Kerschbaumer, M., Tramutoli, V., \& Tzouvaras, M. (2020). Copernicus knowledge and innovation hubs. The International Archives of the Photogrammetry, Remote Sensing and Spatial Information Science, XLIII-B5-2020. Commission V, WG VI/2.

Rowe, A., Dong, L., Landon, J., \& Rezkalla, E. (2019). Scaling start-ups: challenges in Canada's innovation ecosystem. Paper presented at ISPIM Connects Ottawa, 7-10 April, 2019, Canada.

Sambuli, N., \& J. P. Whitt. (2017). Technology innovation hubs and policy engagement: making all voices count. Research Report. Brighton: IDS.

Szogs, A., \& Mwantimwa, K. (2009). Technological capability building in informal firms in the agricultural subsistence sector in Tanzania: assessing the role of Gatsby Clubs. African Journal of Science, Technology, Innovation and Development, 1 (2-3), 115-135.

Toivonen, T., \& Friederici, N. (2015). Time to define what a "hub" really is." Stanford Social Innovation Review, Accessed July 1, 2017. http://www.ssireview.org/blog/en-try/time_to_ define_what_a_hub_really is.

Van Winden, W., Carvalho, L., Van Tuijl, E., Van Haaren, J., \& Van den Berg, L. (2013). Creating Knowledge Locations in Cities: Innovation and Integration Challenges, Routledge, Abingdon.

Wawa, I. (2018). Understanding knowledge systems for innovation: a case of business ideas emanating from innovation centres in Tanzania. Dar es Salaam: STIPRO.

Yeung, V. (2019). Can you, and should you buy an innovation hub? Undergraduate Honor Thesis, 
Stanford University.

Yin, R. K. (1994). Case study research: design and methods. In Applied Social Research Methods, Vol. 5, $2^{\text {nd }}$ ed. Newbury Park, CA: Sage.

Zuniga, P. (2016). Innovation system in development: the case of Peru. MERIT Working Papers 2016-058, United Nations University - Maastricht Economic and Social Research Institute on Innovation and Technology (MERIT) 


\section{Biographies}

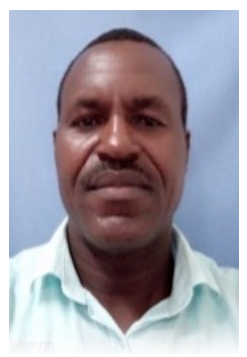

Kelefa Mwantimwa. Dr. Kelefa Mwantimwa is a Senior Lecturer in the Information Studies Unit at the University of Dar es Salaam. He has master's degree in information studies from the University of Dar es Salaam and PhD in Information Science from the University of Antwerp. Kelefa is a multidisciplinary researcher with more that twelve years research experience. His research interests are information, knowledge and innovation systems, and ICTs. He has conducted research and published papers in information, knowledge and innovation systems, and ICTs in socio-economic development.

CRediT Statement: Formal analysis, Conceptualization, Investigation, Methodology, Project administration, Supervision, Validation and Writing Original Draft.

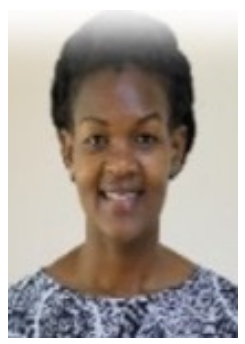

Nora Ndege. Ms. Nora Ndege is an interdisciplinary scholar with more than eight years research experience in inclusive and sustainable development. She is competent in a broad array of issues around innovation, knowledge systems, and contribution to broader topics around science technology and innovation policy. She is a research fellow at the African Centre for Technology Studies and also currently pursuing a PhD in Science, Technology, and Innovation Policy Studies at the University of Sussex, Brighton, United Kingdom. Nora has keen interest in the role of science and innovation in solving Africa's developmental challenges.

CRediT Statement: Formal analysis, Conceptualization, Investigation, Methodology, Project administration, Supervision, Validation and Writing Original Draft.

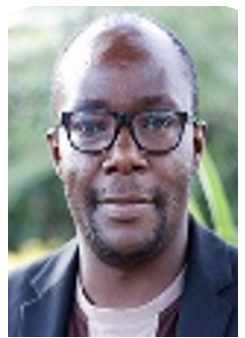

Joanes Atela. Dr. Joanes Atela is an accomplished scholar with over ten (10) years' experience in research and offering technical support to African Governments in resilience, sustainable development, and knowledge management. He is the Convener of the Africa Research and Impact Network (ARIN) - a network of talented researchers and policy makers aimed at promoting dialogue on best research and impact practices. He is also the Programme Director of the Climate Resilient Economies Programme at the African Centre for Technology Studies. Atela has a PhD in Environment and Development from the University of Leeds in the United Kingdom and a master's degree in Agriculture and Resource Management from the University of Bonn in Germany.

CRediT Statement: Conceptualization, Formal Analysis, Investigation, Methodology, Project Administration, Supervision, Validation and Writing Original Draft.

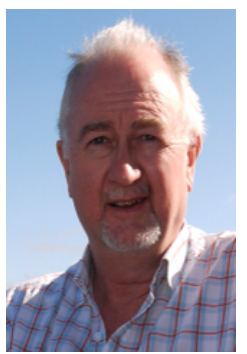

Andrew Hall. Professor Andrew Hall is a science and technology policy analyst with a specialization in the study and design of agriculture innovation processes, policies and practices. He has published extensively on these topics. Andy obtained a PhD from the Science Policy Research Unit at the University of Sussex in 1994. He has held positions at the Ugandan Agricultural Research Institute, the Natural Resources Institute (UK), the International Centre for Research in the Semi-Arid Tropic (ICRISAT), India and the United Nations University Institute for Economics Research on Innovation and Technology (UNU-MERIT), Netherlands/ India, and the Open University, UK. Since 2014 Andy has been a Senior Principal Research Scientist in the Agriculture and Food business unit of the Commonwealth Scientific and Industrial Research Organisation (CSIRO), Australia where his research focuses innovation and transformation in agri-food systems. CRediT Statement: Conceptualization, Formal Analysis, Methodology, Project Administration and Supervision. 